\title{
Igneous geochemical evidence for continuous plate tectonics since $\sim 3.5$ Ga
} \author{
GARBER, J.M ${ }^{1}$; HOLDER, R.H. ${ }^{2,3}$; SMYE, A.J. ${ }^{1}$; REIMINK,
J.R. \\ ${ }^{1}$ Dept. of Geosciences, Penn State University \\ ${ }^{2}$ Dept. of Earth \& Planetary Sciences, Johns Hopkins \\ University \\ 3Dept. of Earth \& Env. Sciences, University of Michigan
}

Continental igneous rock compositions are active tracers of Earth's lithosphere, biosphere, and atmosphere through time. Previous studies of igneous and sedimentary rocks have inferred a significant change in the composition of Earth's continental crust at $\sim 3.0-2.5 \mathrm{Ga}$, possibly suggesting a major transition in global tectonic regime from an Archean stagnant lid to modern plate tectonics. However, other studies have suggested that plate tectonics initiated earlier, with major compositional transitions ascribed to continuous underlying phenomena. To evaluate secular changes in Earth's tectonic regime, we performed a suite of multivariate statistical analyses on continental igneous rocks. We find that continental crust exhibits a clear, statistically separable bimodality throughout the rock record, broadly corresponding to basaltic (mafic) and granitic (felsic) endmembers. The most prominent discontinuous trend in the dataset - the demise of continental komatiites between 3.0-2.5 Ga - attests to the waning of plume-related magmas from the continental record by the end of the Archean. When these distinct magmatic rocks are filtered from the dataset, the remaining data reveal modest $\left(\leq 100^{\circ} \mathrm{C}\right)$ cooling of basaltic sources since the Archean, coupled with decreasing basaltic melt fractions and progressively thickening and oxidizing continental crust. The felsic endmember is more complex but is compatible with the loss of high-pressure TTGs since the late Archean $(\sim 2.7 \mathrm{Ga})$, although the main granitoid compositional trend shows variable peaks around a consistent average. The continuous trends displayed by each endmember suggest that a fundamentally similar version of the same process generating juvenile continental crust today - i.e., mantle melting above subducting slabs - was in operation by $\sim 3.5 \mathrm{Ga}$, and has been the dominant tectonic mode since $\sim 2.5 \mathrm{Ga}$. Finally, two trends link lithospheric evolution to the rise of oxygen and complex life: the abrupt loss of continental komatiites removed a significant oxygen sink in the period preceding the Great Oxidation Event $(\sim 3.0-2.5 \mathrm{Ga})$, whereas a continuous, exponential rise in the $\mathrm{P}_{2} \mathrm{O}_{5}$ content of continental basalts suggests that phosphorus availability has increased significantly over geologic time. 